\title{
PERANCANGAN SISTEM INFORMASI APLIKASI RT RW DI WILAYAH PONDOK RANGGON BERBASIS JAVA
}

\author{
Arohman $^{1}$, Dona Katarina ${ }^{2}$, Finata Rastic Andrari ${ }^{3}$ \\ ${ }^{1,2,3}$ Universitas Indraprasta PGRI \\ Jl. Raya Tengah No. 80, RT.6/RW.1, Gedong, Kec. Pasar Rebo, Jakarta Timur 13760 \\ 1.arrohman1502@gmail.com, ${ }^{2}$ dona.katrin@gmail.com, ${ }^{3}$ fina.rastic@gmail.com
}

\begin{abstract}
ABSTRAK
Aplikasi Rukun Tetangga Rukun Warga sebagai media untuk memudahkan pekerjaan Rukun Tetangga dalam melakukan pengolahan data kependudukan, data penduduk lahir, data penduduk mati, data penduduk pindah, dan data penduduk datang. Untuk membuat sistem dengan memanfaatkan sumber daya yang ada, baik dari segi perangkat lunak (software), perangkat keras (hardware), maupun pemakai atau pengguna (user). Untuk menimalisir kesalahan-kesalahan data yang diakibatkan oleh human error. Solusi penyelesaian yang terjadi adalah dengan menggunakan metode grounded research. Hasil dari penelitian ini adalah sistem Informasi aplikasi RT RW yang dapat membantu kinerja pengurus lingkungan RT 006 RW 03 dalam melakukan kegiatan-kegiatan pendataan seperti pendataan penduduk, pendataan kelahiran, pendataan kematian, pendataan pindah, dan pendataan datang sehingga dapat dilakukan dengan cepat dan efisien.
\end{abstract}

Kata Kunci: Perancangan, Sistem Informasi, Aplikasi, RT RW

\begin{abstract}
The Neighbourhood Hamlet application is a medium to facilitate the work of the Neighbourhood in processing population data, birth population data, dead population data, moving population data, and incoming population data. To create a system by utilizing existing resources, both in terms of software (software), hardware (hardware), and users or users (users). To minimize data errors caused by human error. The solution that occurs is to use the grounded research method. The results of this study are the RT RW application information system that can help the performance of RT $006 R W 03$ environmental management in carrying out data collection activities such as population data collection, birth data collection, death data collection, moving data collection, and incoming data collection can be done quickly and efficiently.
\end{abstract}

Key Word: Design, Information Systems, Applications, RT RW

\section{PENDAHULUAN}

RT/RW adalah lembaga kemasyarakatan, yaitu lembaga yang dibentuk melalui musyawarah masyarakat setempat (Sumadiono, 2018). RT 006 RW 03 merupakan salah satu RT dari Kelurahan Pondok Ranggon Kecamatan Cipayung yang bergerak dalam bidang pelayanan terhadap warga, memiliki permasalahan tersendiri dalam pengelolaan data penduduk, sistem yang berjalan saat ini hanya menggunakan buku induk dan disimpan dalam bentuk arsip.

Keberadaan dokumen penduduk tentunya berpindah seiring dengan pergantian kepengurusan. Kendala yang alami oleh RT adalah sistem informasi yang tidak efektif dan efisien, sehingga menyulitkan dan memperlambat dalam proses pelaporan dan perarsipan data kependudukan (Setiawan \& Mahendra, Setya, Agus, 2015). Pengelolaan data penduduk seperti pencatatan data kelahiran, data kematian, data kepindahan dan data kedatangan penyimpanannya masih dalam buku arsip sehingga menumpuk dan sulit dalam pencarian data (Agustia \& Nelisa, 2013). Kesalahan dalam mendata penduduk dikarenakan dalam pengolahannya masih dengan proses yang konvensional (Fujiyati, 2013). Sistem yang berjalan selama ini memungkinkan adanya kesalahan, membutuhkan waktu yang lama dalam proses pencarian data (Priyanti \& Iriani, 2013).

Misalnya, ketika terdapat warga yang ingin membuat surat pengantar, Ketua RT kerap kesulitan dalam mencari data warga tersebut atau ketika watga yang ingin pindah, datang, lahir, ataupun meninggal. Akan sangat memakan waktu dalam proses perubahan data tersebut. Banyaknya kertas yang digunakan menyebabkan kesulitan dalam hal penyimpanan berkas, selain itu kertas cenderung mudah rusak dan hilang. 
Berdasarkan pada uraian permasalahan tersebut, peneliti termotivasi untuk merancang suatu sistem, melalui sistem informasi pendataan penduduk agar lebih efisien dan efektif khususnya di RT 006 RW 03 berbasis java. Dengan dibuatnya sistem ini diharapkan dapat mempermudah pengurus dalam mengelola data agar lebih cepat, ketetapan dalam pengelolaan data dan meningkatkan keakuratan data.

Sistem merupakan suatu kumpulan komponen-komponen yang membentuk satu kesatuan (Tyoso, 2016). Sistem secara umum mempunyai makna sebagai suatu rangkaian yang terdiri dari berbagai elemen yang saling berinteraksi untuk mencapai tujuan tertentu (Mahatmyo, 2014). Sistem merupakan suatu jaringan kerja dari prosedur-prosedur yang saling berhunungan, berkumpul bersama untuk melakukan kegiatan atau untuk melakukan sasaran tertentu (Arif, 2016). Informasi adalah data yang telah diklarifikasikan atau diolah atau diinterpretasikan untuk digunakan dalam proses pengambilan keputusan (Sutabri, 2012).

Tujuan Penelitian ini adalah untuk merancangan suatu sistem yang tekomputerisasi dengan aplikasi berbasis java netbeans yang tersikronisasi database sehingga dapat mendukung terciptanya menajemen data yang baik. Database Management System (DBMS) merupakan paket program (software) yang dibuat agar memudahkan dan membuat efisien pemasukan, pengeditan, penghapusan dan pengambilan informasi terhadap databsase (Yanto, 2016).

Adapun manfaat dari penelitian ini adalah untuk menghasilkan sebuah sistem informasi pengelolaan data penduduk yang cepat, tepat, akurat, efektif dan efisien (Priyanti \& Iriani, 2013). Dengan adanya sistem yang terkomputerisasi dalam pendataan penduduk akan mempermudah pencatatan dan mengurangi kesalahan data.

\section{METODE PENELITIAN}

Peneliti menggunakan metode grounded research yaitu suatu metode penelitian yang mendasarkan diri kepada fakta yang menggunakan analisis perbandingan untuk mengadakan generalisasi teori, dan mengembangkan teori dimana pengumpulan data dan analisis data berjalan pada waktu yang bersamaan.

Metode penggunaan ini dapat dilaksanakan melalui:

Studi Lapangan, dengan melakukan studi berdasarkan data primer dari perusahan/intansi yang diteliti yaitu RT 006 RW 03 Pondok Ranggon dengan cara mengadakan:

Wawancara (Interview)

Tahap awal wawancara ini dimulai dengan meminta izin kepada Bapak Ahmad Saidun selaku ketua RT 006 RW 03 tersebut untuk melakukan penelitian dan bertanya secara langsung kepada beliau mengenai prosedur dan langkahlangkah mengenai kondisi sistem saat ini dan kami juga meminta izin bertanya secara langsung kepada beberapa pengurus lainnya untuk mendapatkan informasi mengenai hal-hal yang dibutuhkan dalam proses penelitian.

Pengamatan (observasi)

Pengamatan dilakukan untuk memahami sistem yang sedang berjalan untuk mendapatkan kesimpulan dari masalah yang bertujuan untuk perancangan suatu sistem. Pengamatan ini dilakukan pada 1 April 2021 sampai 22 April 2021, bertempat di RT 006 RW 03 Pondok Ranggon Jakarta Timur. Penulis mengamati sistem pelayanan penduduk di RT 006 RW 03 meninjau tentang bagaimana pengelolaan data penduduk, pengelolaan data kelahiran, pengelolaan data kematian, pengelolaan data penduduk pindah, pengelolaan data penduduk datang sehingga penulis dapat menyimpukan masalah-masalah yang bertujuan untuk merancang sistem selanjutnya.

Studi kepustakaan, dengan melakukan studi berdasarkan refrensi dan berbagai diskusi pemahaman baik dengan dosen pembimbing, pihak perusahaan maupun dengan orang yang berkompeten pada studi kasus ini. Penulis juga melakukan studi dari berbagai buku, diklat, modul serta internet yang memuat informasi yang dibutuhkan dalam menunjang penelitian. 
Berikut ini adalah langkah-langkah pengembangan sistem yang digunakan peneliti :

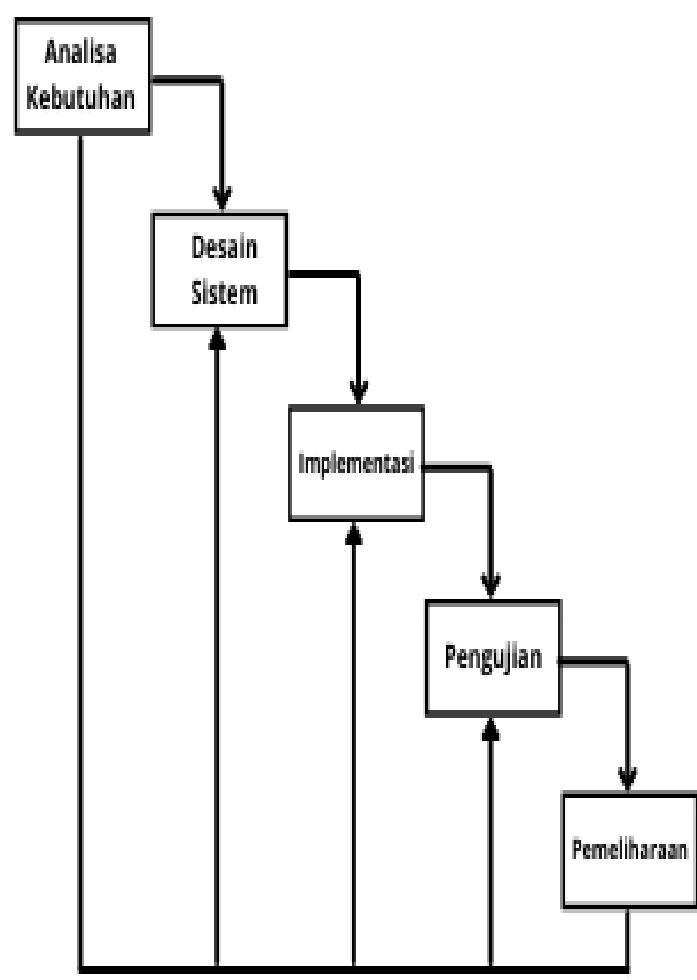

Gambar 1. Metode Waterfall

\section{HASIL DAN PEMBAHASAN}

Hasil dari penelitian pada RT 006 RW 03 nantinya akan dirancang suatu sistem informasi dengan menggunakan teknologi komputer yang sedang berkembang saat ini, jadi proses pemasukan data, pencarian data, dan perubahan data pengolaan penduduk tidak menggunakan cara manual lagi, sehingga prosesnya bisa menjadi lebih cepat, tepat, akurat dan menjadi lebih efektif dan efisien dalam pengerjaanya. Dikarenakan sistem yang digunakan belum terkomputerisasi maka penulis merancang database untuk sistem informasi sehingga mempermudah dalam penyimpanan data dan pencarian data, sehingga tidak menggunakan media kertas lagi dan dapat membuat sistem yang mudah dipahami oleh setiap user agar dapat digunakan pada sistem informasi aplikasi RT RW.
Diagram Konteks Sistem yang Diusulkan

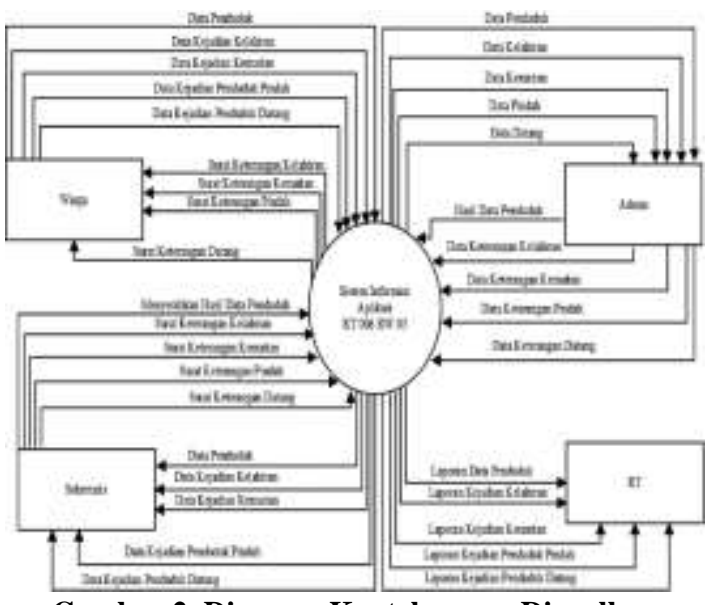

Gambar 2. Diagram Konteks yang Diusulkan

\section{Entity Relationship Diagram (ERD)}

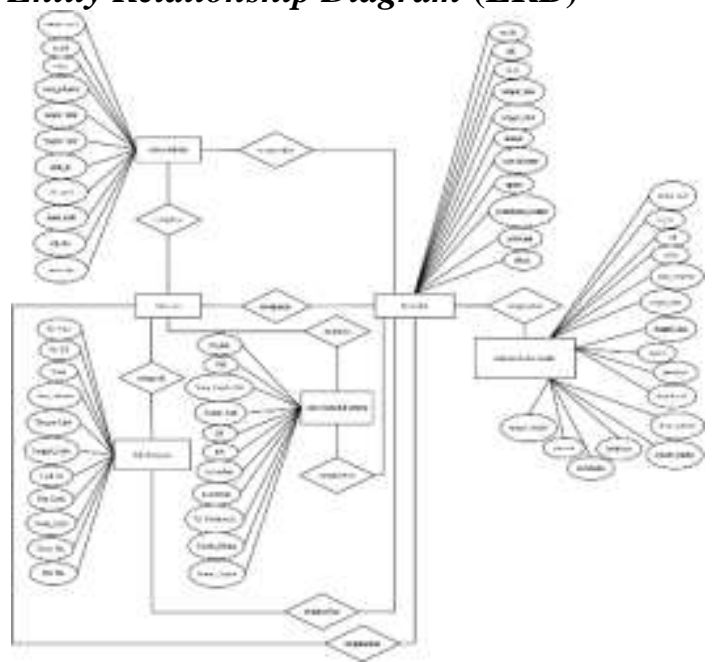

Gambar 3. Entity Relationship Diagram (ERD)

\section{Tampilan Layar Menu Login}

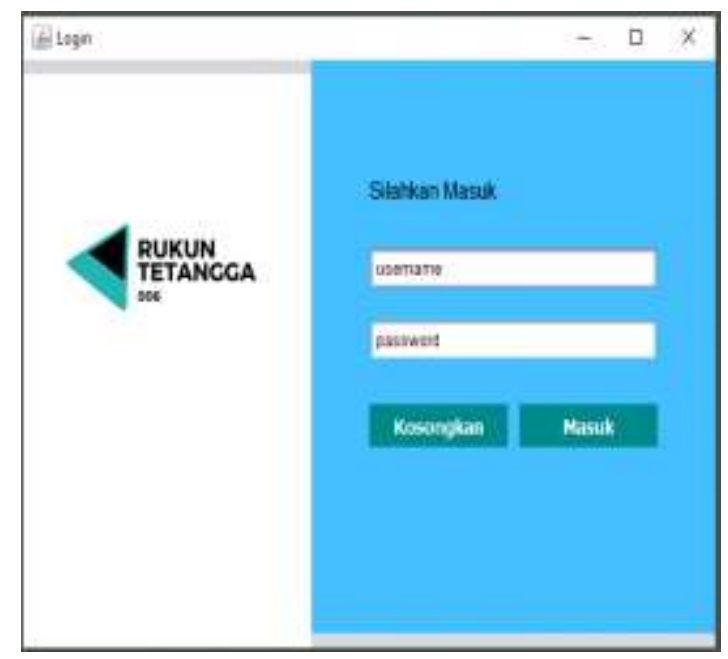

Gambar 4. Tampilan Layar Menu Login

Pada gambar diatas adalah tampilan layar menu login pada sistem informasi aplikasi RT 006 RW 03, terdapat username dan password. 


\section{Tampilan Layar Menu Utama}

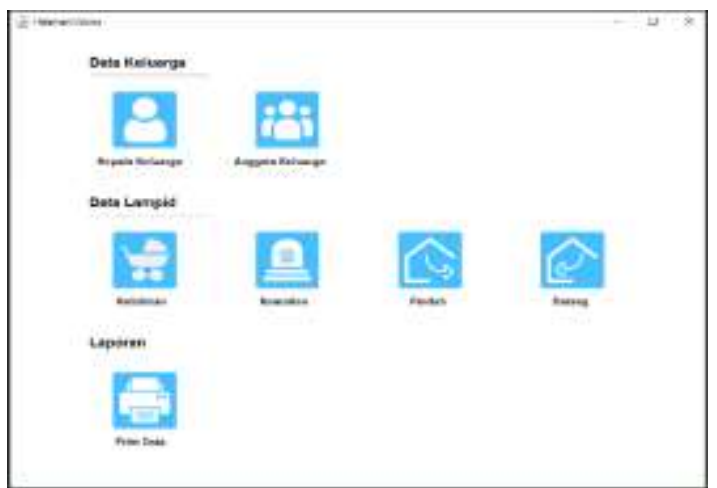

Gambar 5. Tampilan Layar Menu Utama

Pada gambar diatas adalah tampilan layar menu utama pada sistem informasi aplikasi RT 006 RW 03, terdapat 7 menu bar yaitu data kepa keluarga, data anggota keluarga, data kelahiran, data kematian, data pindah, data datang, laporan.

\section{Tampilan Layar Data Kepala Keluarga}

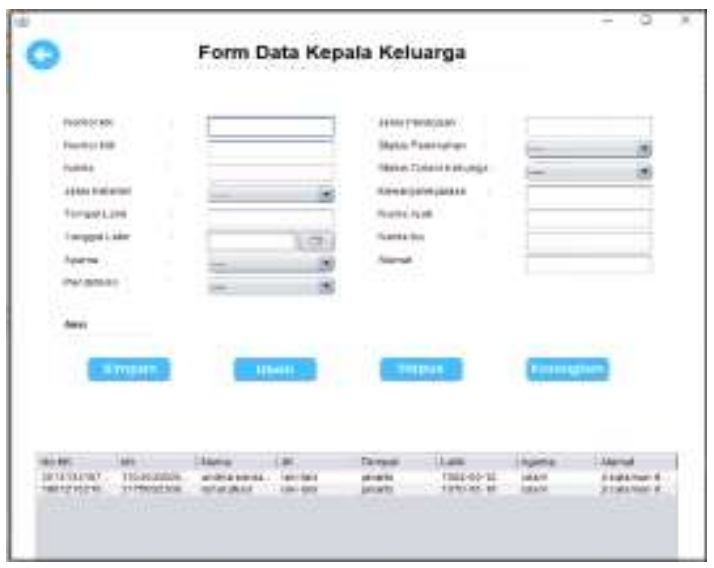

Gambar 6. Tampilan Layar Data Kepala Keluarga

Pada gambar diatas adalah tampilan layar data kepala keluarga pada sistem informasi aplikasi RT 006 RW 03.

\section{Tampilan Layar Data Anggota Keluarga}

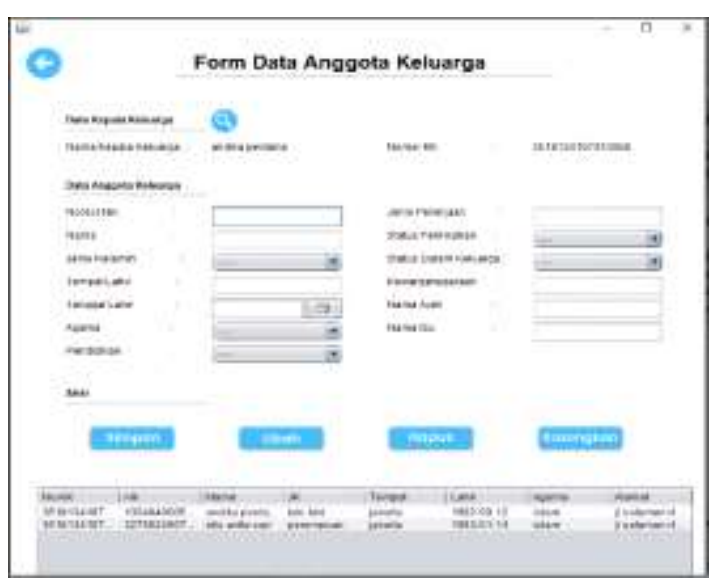

Gambar 7. Tampilan Layar Data Anggota Keluarga
Pada gambar diatas adalah tampilan layar data anggota keluarga pada sistem informasi aplikasi RT 006 RW 03.

\section{Tampilan Layar Data Kelahiran}

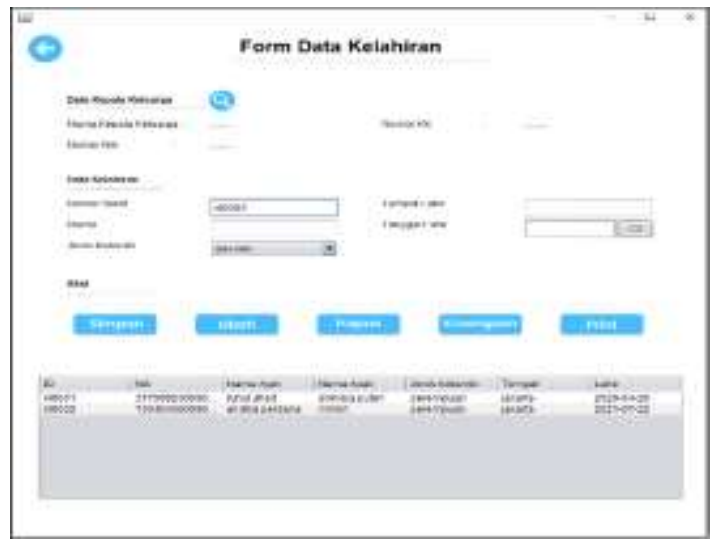

Gambar 8. Tampilan Layar Data Kelahiran

Pada gambar diatas adalah tampilan layar data kelahiran pada sistem informasi aplikasi RT 006 RW 03.

\section{Tampilan Layar Data Kematian}

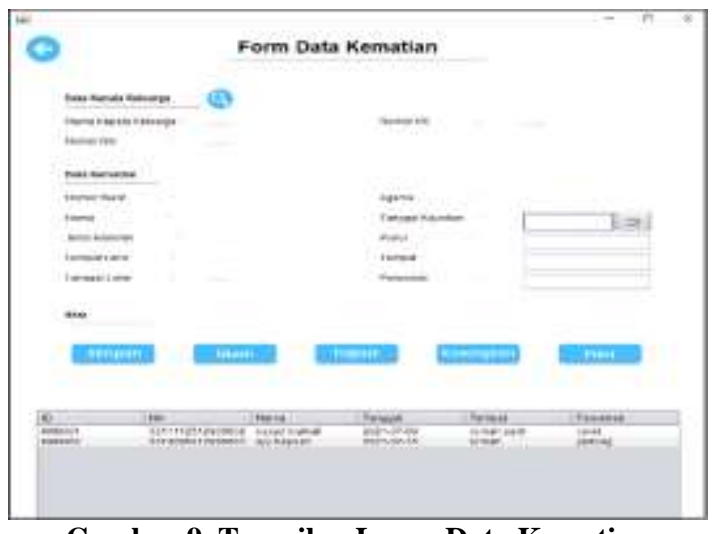

Gambar 9. Tampilan Layar Data Kematian

Pada gambar diatas adalah tampilan layar data kematian pada sistem informasi aplikasi RT 006 RW 03.

\section{Tampilan Layar Data Pindah}

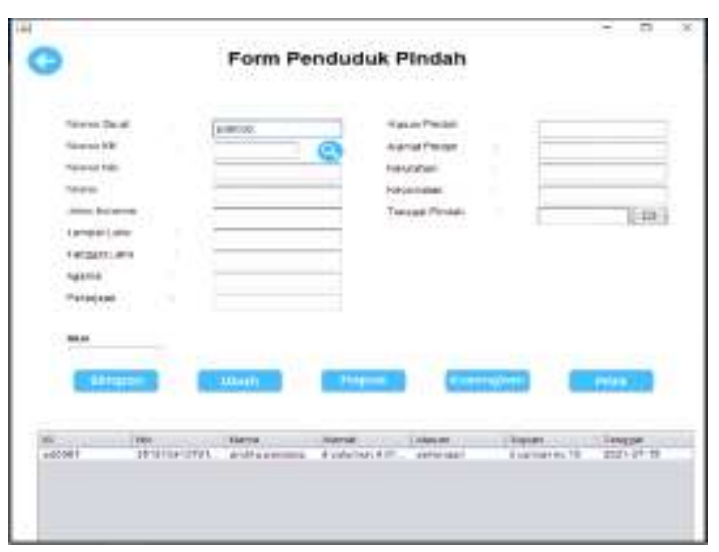

Gambar 10. Tampilan Layar Data Pindah

16o | Perancangan Sistem Informasi Aplikasi RT RW Di Wilayah Pondok Ranggon 
Pada gambar diatas adalah tampilan layar data penduduk pindah pada sistem informasi aplikasi RT 006 RW 03.

\section{Tampilan Layar Data Datang}

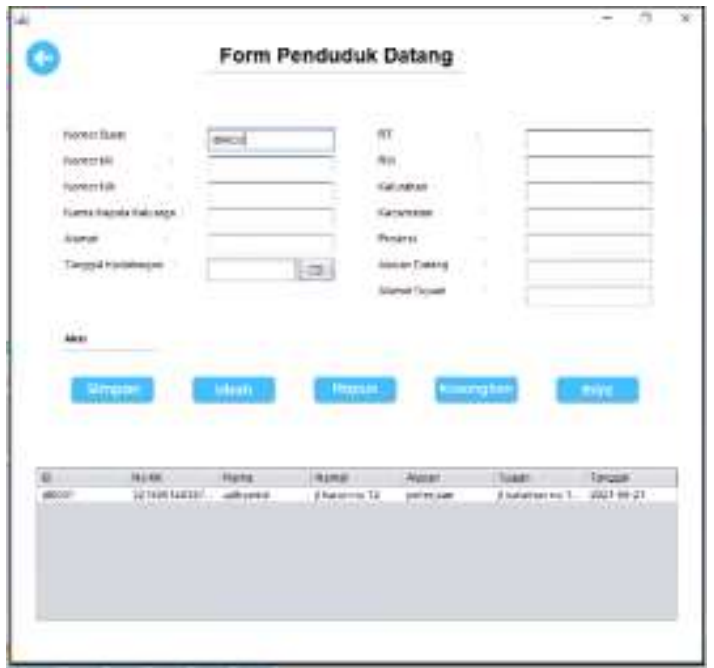

Gambar 11. Tampilan Layar Data Datang

Pada gambar diatas adalah tampilan layar data penduduk datang pada sistem informasi aplikasi RT 006 RW 03.

\section{Tampilan Layar Laporan Data Penduduk}

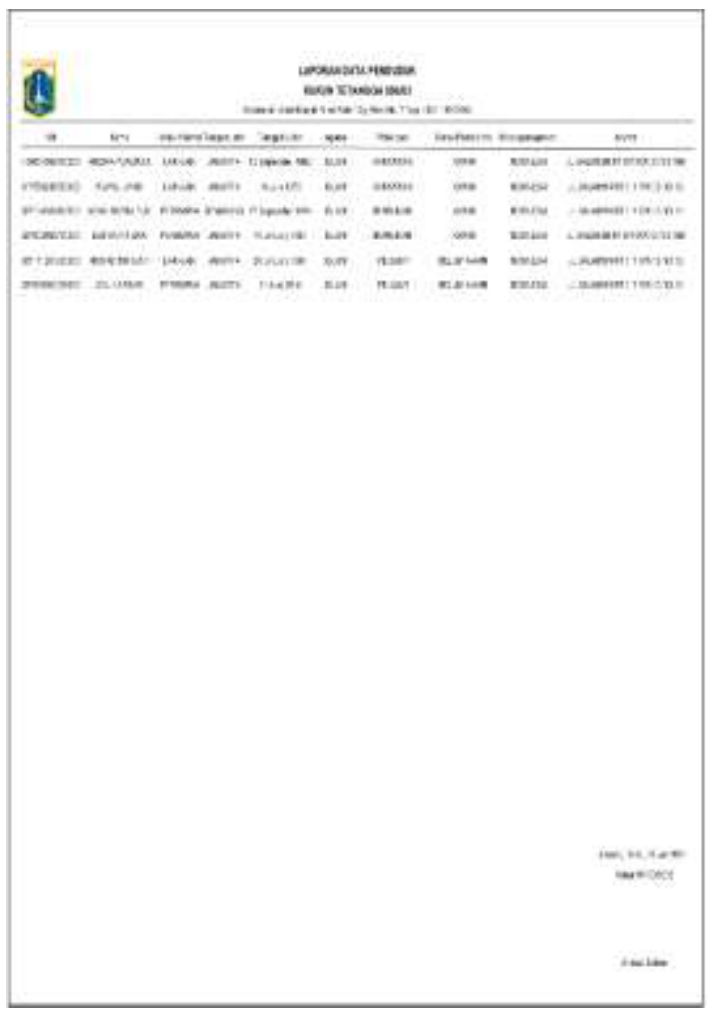

Gambar 12. Tampilan Layar Laporan Data Penduduk

Pada gambar diatas adalah tampilan layar laporan data penduduk pada sistem informasi aplikasi RT 006 RW 03.
Tampilan Layar Laporan Data Kelahiran

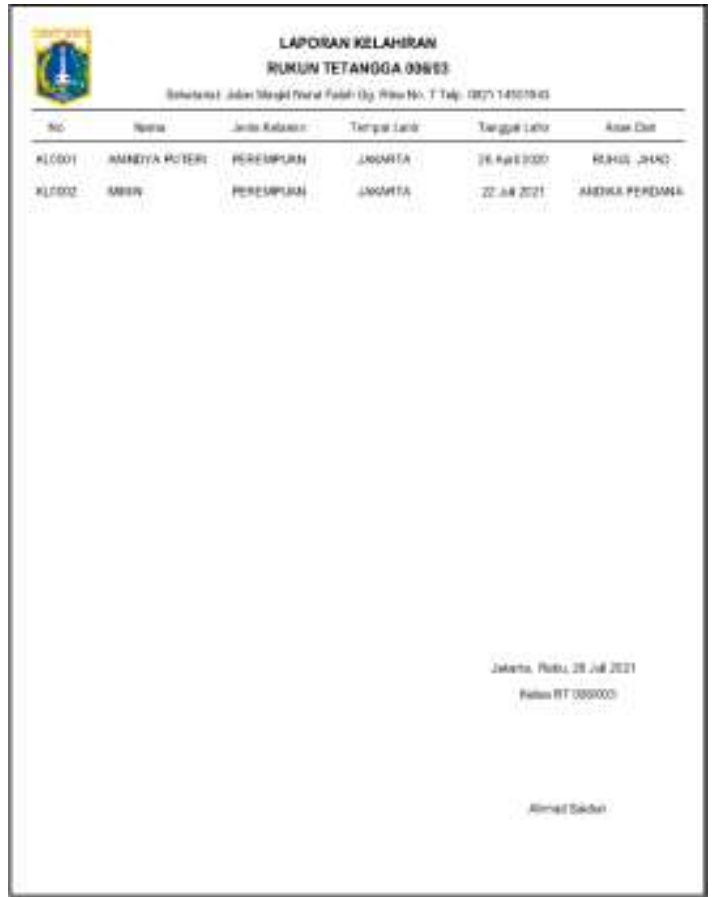

Gambar 13. Tampilan Layar Laporan Data Kelahiran

Pada gambar diatas adalah tampilan layar laporan data kelahiran pada sistem informasi aplikasi RT 006 RW 03.

\section{Tampilan Layar Laporan Data Kematian}

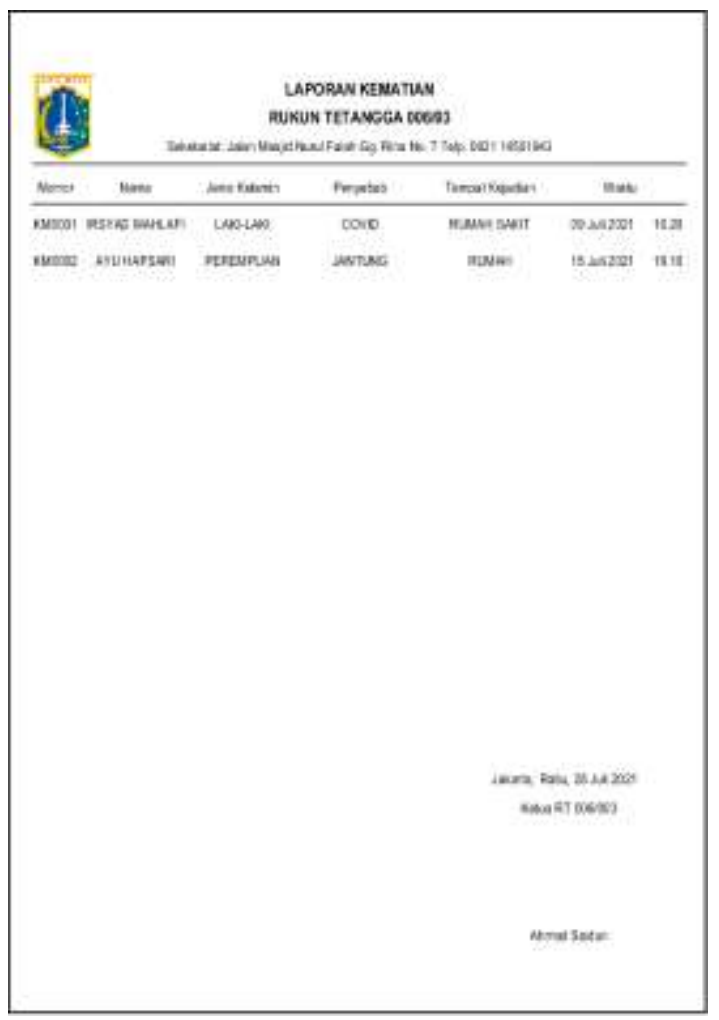

Gambar 14. Tampilan Layar Laporan Data Kematian 
Pada gambar diatas adalah tampilan layar laporan data kematian pada sistem informasi aplikasi RT 006 RW 03.

\section{Tampilan Layar Laporan Data Pindah}

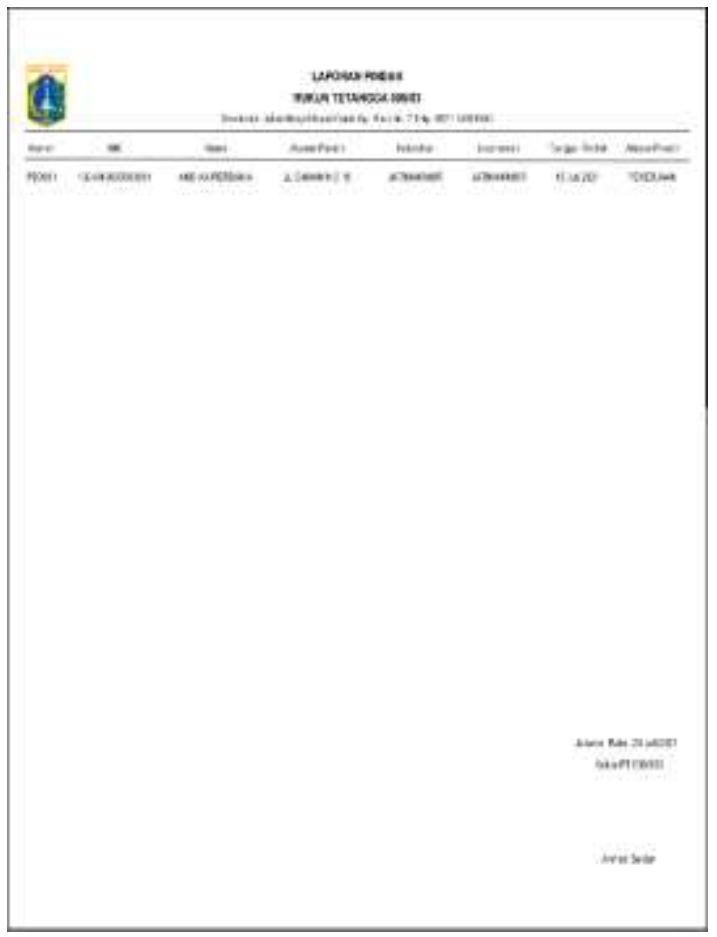

Gambar 15. Tampilan Layar Laporan Data Pindah

Pada gambar diatas adalah tampilan layar laporan data pindah pada sistem informasi aplikasi RT 006 RW 03.

\section{Tampilan Layar Laporan Data Datang}

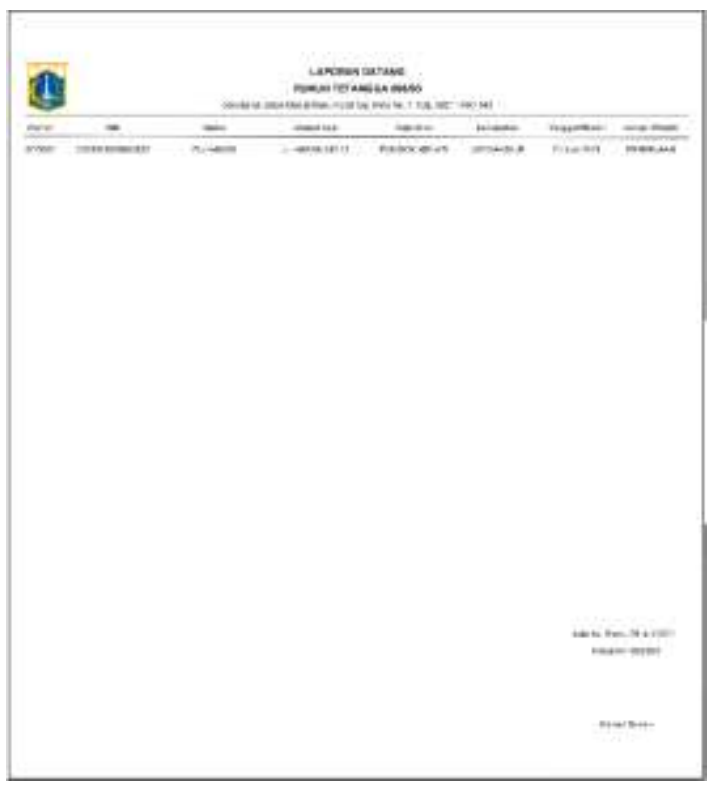

Gambar 16. Tampilan Layar Laporan Data Datang

Pada gambar diatas adalah tampilan layar laporan data datang pada sistem informasi aplikasi RT 006 RW 03.

\section{SIMPULAN DAN SARAN}

Berdasarakan hasil penelitian yang penulis lakukan mengenai perancangan sistem informasi aplikasi RT RW di wilayah pondok ranggon berbasis Java Netbeans adalah RT dapat mengoperasikan aplikasi tersebut dengan mudah tanpa menemui kendala yang berarti.

sistem informasi aplikasi RT ini dapat memberikan informasi yang lebih tepat, cepat, dan akurat dibandingkan dengan sistem manual yang diberlakukan di instansi ini. Penggunaan sistem komputerisasi dapat membantu pihak RT dalam mempercepat proses-proses pengolahan data penduduk sehingga kekurangan pada sistem lama dapat teratasi.

Sistem ini juga dapat mengurangi kesalahankesalahan manusia (human eror). Memudahkan pelayanan kepada warga yang mengenai pembuatan berkas sehingga dapat meningkatkan efisiensi dari berbagai kegiatan.

Sistem informasi aplikasi RT dapat mempersingkat waktu pengerjaan dalam membuat surat. Sistem informasi aplikasi RT juga dapat mempermudah dalam memberikan informasi berupa data penduduk dan data kejadian di wilayah.

Berdasarkan simpulan di atas, bahwa penelitian ini masih kurang dari kata sempurna, terdapat beberapa macam aspek yang perlu ditingkatkan untuk menyempurnakan sistem informasi aplikasi RT ini, maka terdapat beberapa saran yag ingin penulis sampaikan untuk menunjang penelitian lebih lanjut di antaranya tampilan aplikasi yang dibuat masih sangat sederhana, diharapkan kepada penelitian selanjutnya dapat dikembangkan lagi sehingga dapat membuat pengurus lingkungan tidak membuat kesalahan laporan data-data.

Perlu ditambahkannya fasilitas forum diskusi sebagai sarana bertukar pikiran maupun informasi seputar lingkungan antara pengurus lingkungan dengan warga maupun warga satu dengan warga lainnya.

\section{UCAPAN TERIMAKASIH}

Peneliti mengucapkan terimakasih kepada Ketua RT 006 RW 03 Pondok Ranggon, 
Seketaris RT 006 RW 03, dospem pembimbing materi maupun teknik, keluarga, dan teman-teman yang telah memberikan kerjasama yang baik dalam penelitian ini.

\section{DAFTAR PUSTAKA}

Agustia, S. D., \& Nelisa, M. (2013). Sistem Penataan Arsip Dinamis Inaktif di Badan Kepegawaian Daerah Kabupaten Padang Pariaman. Ilmu Informasi Perpustakaan Dan Kearsipan, 2(1), 299-304.

Arif, M. (2016). Bahan Ajar Rancangan Teknik Industri. Deepublish.

Fujiyati, O. Y. (2013). Sistem Informasi Pengolahan Data Kependudukan Di Desa Purwoasri. Speed-Sentra Penelitian Engineering Dan Edukasi, 7(1), 1-8.

Mahatmyo, A. (2014). Sistem Informasi Akuntansi Suatu Pengantar. Deepublish.

Priyanti, D., \& Iriani, S. (2013). Sistem Informasi Data Penduduk Pada Desa Bogoharjo Keccamatan Ngadirojo Kabupaten Pacitan. IJNS-Indonesian Journal on Networking and Security, 2(4), 55-61.

Setiawan, D., \& Mahendra, Setya, Agus, Y. (2015). Perancangan Sistem Informasi Penduduk Pada Kantor Desa Kebonsari. IJNS - Indonesian Journal on Networking and Security, 4(2), 21-26.

Sumadiono, W. (2018). Pedoman Umum Organisasi dan Administrasi Rukun Warga Rukun Tetangga. Deepublish.

Sutabri, T. (2012). Analisis sistem informasi. Penerbit Andi.

Tyoso, J. S. P. (2016). Sistem Informasi Manajemen. Deepublish.

Yanto, R. (2016). Manajemen Basis Data Menggunakan MySQL. Deepublish. 